\title{
Drilled Shaft Performance in Cemented Calcareous Formations In the Southeast US
}

\author{
Dan Brown ${ }^{1}$, M.ASCE, Ph.D., P.E., and W. Robert Thompson, III, ${ }^{2}$ M.ASCE, P.E.
}

${ }^{1}$ President, Dan Brown and Associates, PLLC, 300 Woodland Road, Sequatchie, TN 37374; Phone: 423-942-8681; dbrown@ danbrownandassociates.com

${ }^{2}$ Principal, Dan Brown and Associates, PLLC, 2400 Old Creek Road, Montgomery, AL 36117; Phone: 334-239-3135; rthompson@danbrownandassociates.com

\begin{abstract}
Cemented calcareous formations, typically referred to as chalk or marl, are widespread in the southeastern U.S. and are ideally suited to the use of drilled shaft foundations. Chalk formations are relatively stable in an open borehole and are relatively easy to drill but difficult to penetrate with driven piling. These cohesive intermediate geomaterials are sometimes difficult to characterize for design purposes because of the difficulty in sampling and testing. This paper provides a review of recent instrumented load tests performed in these cemented calcareous materials. A total of 15 tests were selected from southeastern states based on the availability of good quality load test data and geotechnical information. Most of the test data include measurements of compressive strength from cores. Ultimate unit side shear and end bearing resistance is found to show a relationship with unconfined compressive strength using existing published correlations for weak rock materials.
\end{abstract}

\section{INTRODUCTION}

As a part of ongoing research sponsored by the ADSC Industry Advancement Fund, researchers at several universities are performing an evaluation of design methods using drilled shaft load test data from around the U.S. This article provides a review of data from cemented calcareous formations, typically referred to as chalk or marl. Similar studies are ongoing for other types of rock and intermediate geomaterials.

These chalk materials are typically massive and often have the appearance of hard clay or very soft rock. Microfossils are typically abundant, as evident in the scanning electron micrograph of a marl sample from Charleston, SC shown in Figure 1. Sand may be present in varying amounts, as well as phosphate and clay minerals.

Sampling can be difficult, as the chalks are typically too hard to sample with pushed tube samplers. Rock core sampling techniques can sometimes be used, but cores of softer chalks are easily damaged when using rock coring techniques. 
Common practices include standard penetration tests (although SPT N-values of greater than 50 blows per $0.3 \mathrm{~m}$ (foot) are common) and pitcher-barrel coring samplers as shown in the photos of Figure 2.

Load tests that were selected for inclusion in this study are based on a review of data collected from Loadtest, Inc., the Alabama Department of Transportation, the Mississippi Department of Transportation, and available literature. A total of 15 tests were selected from southeastern states, based on the availability of good quality load test data and geotechnical information. A case history summary of each load test is included in Brown and Thompson (2008) as are the reference citations of the load tests and geotechnical reports for each test.

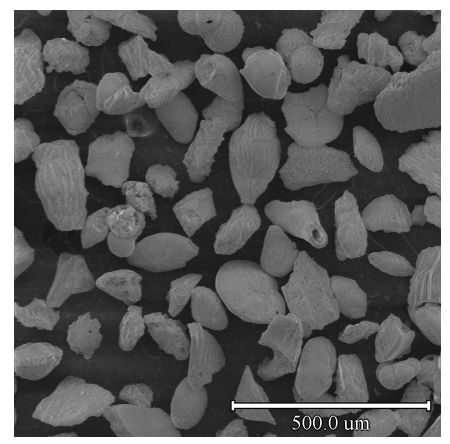

FIG. 1. SEM Photograph of a Cooper Marl Sample (Camp, 2004)
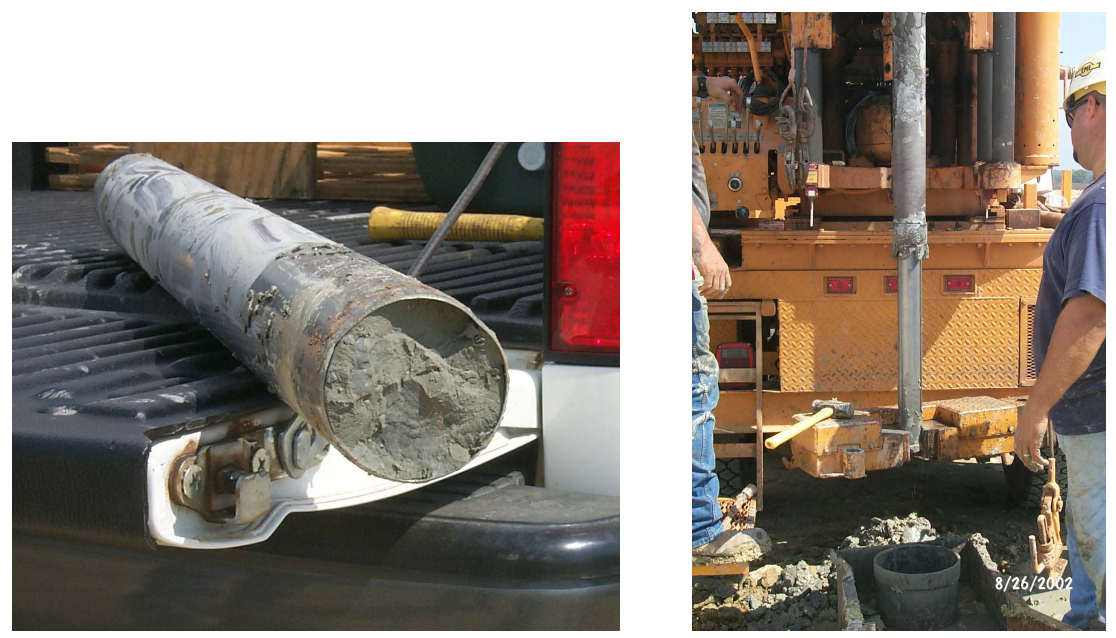

FIG. 2. Pitcher Barrel Sample of Chalk from Alabama 


\section{ANALYSIS}

Analyses of load test data can be complicated by the lack of consistency of the types of data collected, particularly in strength data used to characterize the geomaterials. The unconfined compressive strength, or $q_{u}$, is typically used to describe hard cohesive soils and soft rocks.

The collected load test data listed in Table 1 has values of $q_{u}$ ranging from 138.9 to $6080 \mathrm{kPa}$ (2.9 to $127 \mathrm{ksf})$. Some sites had SPT data available. Except for the tests in Cooper Marl, SPTs (where performed) were usually recorded as $100+$ blows per 0.3 $\mathrm{m}$ (foot), or refusal. The sites in the Cooper Marl tended to have blow counts less than 50 blows per $0.3 \mathrm{~m}$ (foot). The US 80 project site in Alabama had only SPT data; an estimated $q_{u}=2150 \mathrm{kPa}(45 \mathrm{ksf})$ was used for analyses based on correlations from nearby projects.

\section{Side Shear}

Turner (2006) summarized several basic formulas for estimating ultimate unit side shear resistance utilizing a correlation between ultimate unit side shear, $f_{s}$, and the square root of the unconfined compressive strength, $q_{u}$. These relationships may be expressed in a dimensionless form by normalizing compressive strength by atmospheric pressure as shown in (1):

Unit Side Resistance:

$$
f_{s}=C \cdot p_{a} \cdot \sqrt{\frac{q_{u}}{\left(p_{a}\right)}}
$$

where $p_{a}$ is atmospheric pressure and $\mathrm{C}$ is an empirical constant.

Correlations of this type have been applied to rock sockets in shale, mudstone, claystone, limestone, and marl. Horvath and Kenny (1979) first proposed such a relationship, with an empirical constant ranging from 0.65 to 1 for smooth to rough sockets (with their original expression adjusted to the units normalized by $p_{a}$ as indicated above). Rowe and Armitage (1987) proposed a similar expression with different constants, and Kulhawy and Phoon (1993) evaluated a larger database of rock sockets and proposed values of $\mathrm{C}$ ranging from 1 to 3 depending upon sidewall roughness and degree of weathering. An updated evaluation of these test data by Kulhawy et al (2005) suggests that a value of $C=1$ represents the mean estimate of design ultimate side shear resistance, based on the most up-to-date analysis of the available data. 


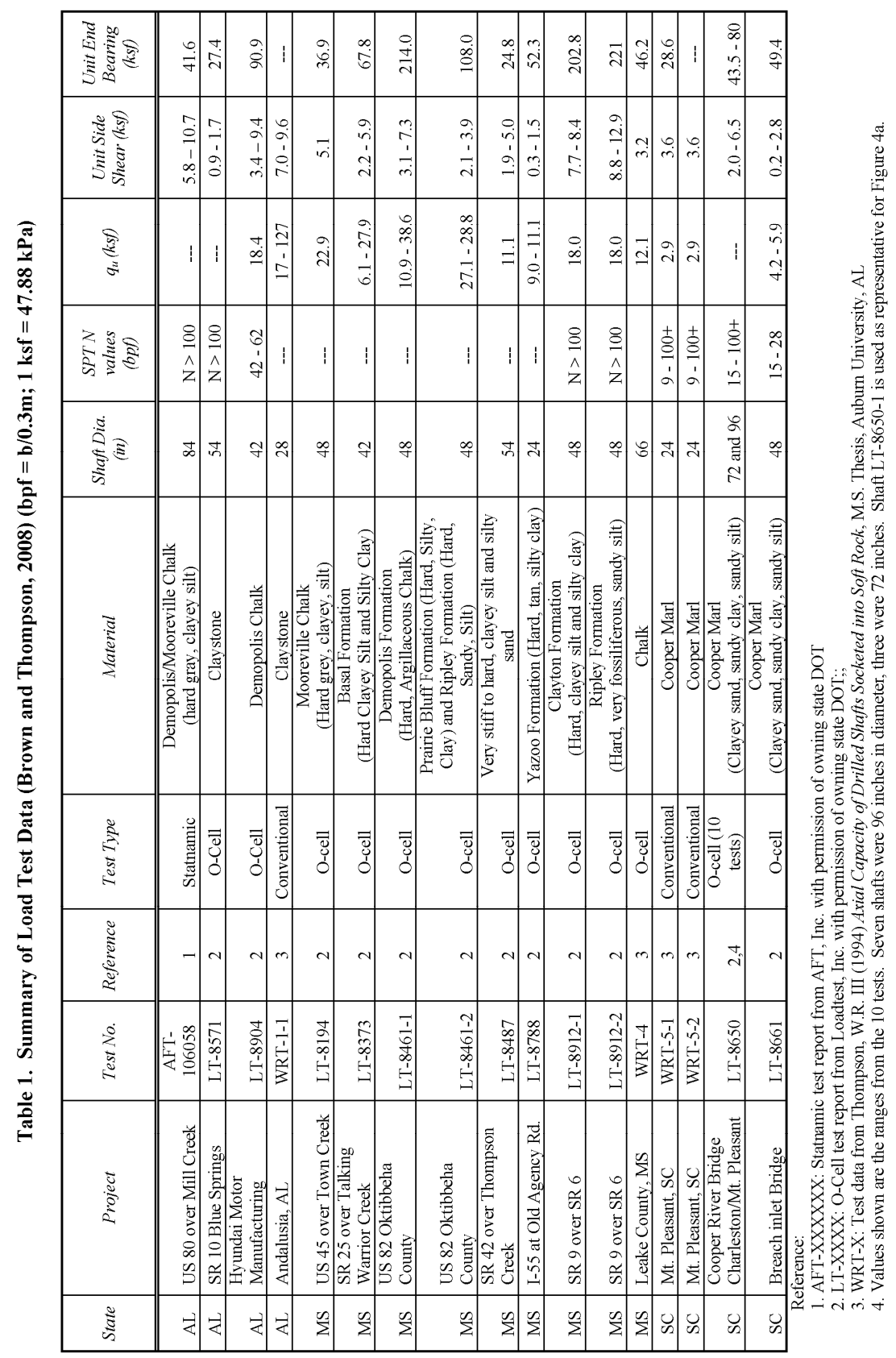


The Horvath \& Kenney relationship is compared with measured unit side resistance from the data evaluated in this study, with the data plotted versus $q_{u}$.on Figure 3. Each test site with $\mathrm{q}_{\mathrm{u}}$ data is shown as a small open symbol. The averages of the groups of tests (Mississippi (MS) Chalk, South Carolina (SC) Cooper Marl, and Alabama (AL) Claystone) are shown in large shaded symbols. The US 80 test is plotted using an estimated value for $q_{u}$. The curve representing the equation derived from the Horvath \& Kenney relation for ultimate unit side shear resistance is shown, with the empirical constant ranging from $\mathrm{C}=0.65$ to 1.0. The data presented in this figure suggest that the relationship provides a reasonably conservative estimate of side shearing resistance with the constant at the lower end of this range (0.65), and a better fit through the mean with $\mathrm{C}=0.85$.

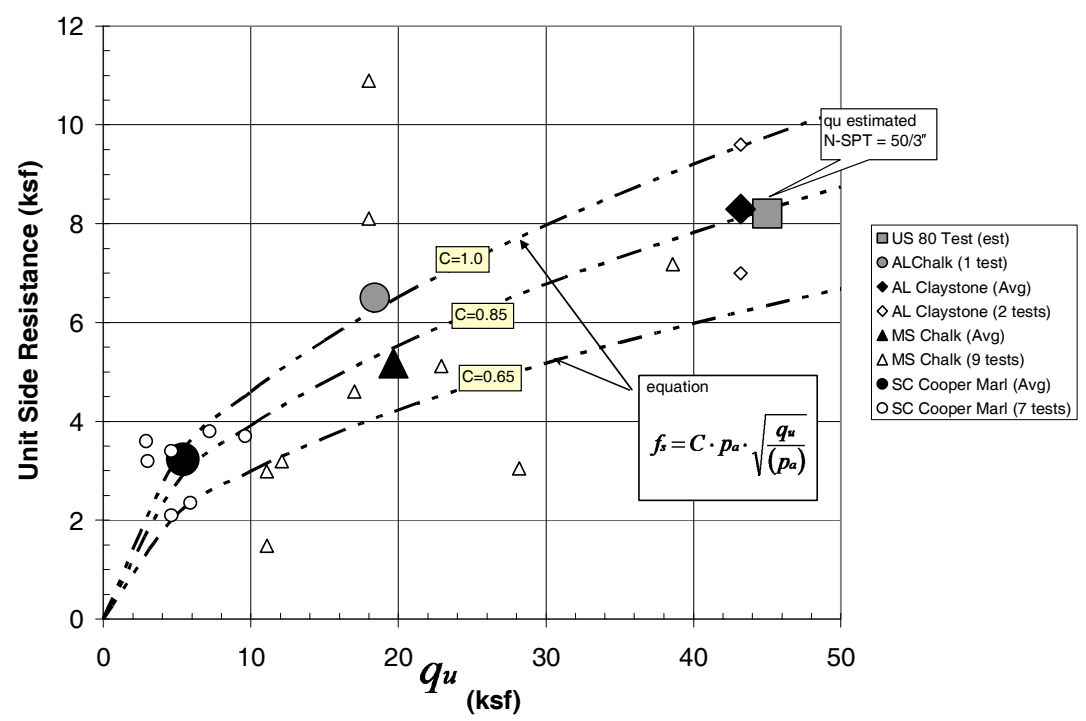

FIG. 3. Unit Side Resistance vs. $q_{u}(100 \mathrm{kPa} \approx 2 \mathrm{ksf})$

\section{End Bearing}

A wide range of expressions are available for relating base resistance to strength parameters of weak rock or marl. The O'Neil and Reese (1999) guidelines for cohesive intermediate geo materials (IGM), which are massive and relatively free of joints, fissures, or weak seams, would suggest a value similar to (2):

Unit Base Resistance:

$$
q_{u l t}=2.5 q_{u}
$$

Since the mobilization of unit base resistance occurs over a much larger range of deflections than unit side resistance, the base resistance data are evaluated from the 
load tests as a function of displacement in terms of the shaft diameter. Figures $4 \mathrm{a}$ and $4 \mathrm{~b}$ illustrate the mobilized unit base resistance from the load tests plotted as a function of displacement. The shaft displacements are normalized by dividing the displacements by the shaft diameter, and thus are expressed as a percent of the shaft diameter. The mobilized unit base resistance was normalized by $q_{u}$.

Two figures were used to plot the data for easier reading. Each test is labeled with the Test No. from Table 1. Three of the tests (LT-8571, WRT-1-1, and WRT-5-2) did not have sufficient end bearing data to plot. The curve labeled LT-8560-1 is plotted as representative of the ten load tests included in Table 1 as LT-8650.

For all but two of the remaining tests, the measured end bearing load-displacement curve was available and is included on the plots. Two tests reached the maximum applied load at a shaft deflection of less than $1 \%$. These are shown as single points on the graphs, and may not have fully mobilized the available base resistance.

The data presented on these figures suggest that the use of the O'Neil and Reese (1999) guideline for cohesive IGM would be conservative in most cases. Some of the data indicate that this guideline could be very conservative; it is possible that the $q_{u}$ data from some of these sites may have been affected by sample disturbance, or that a higher sand content affects the correlation with a simple $q_{u}$ measure of strength.

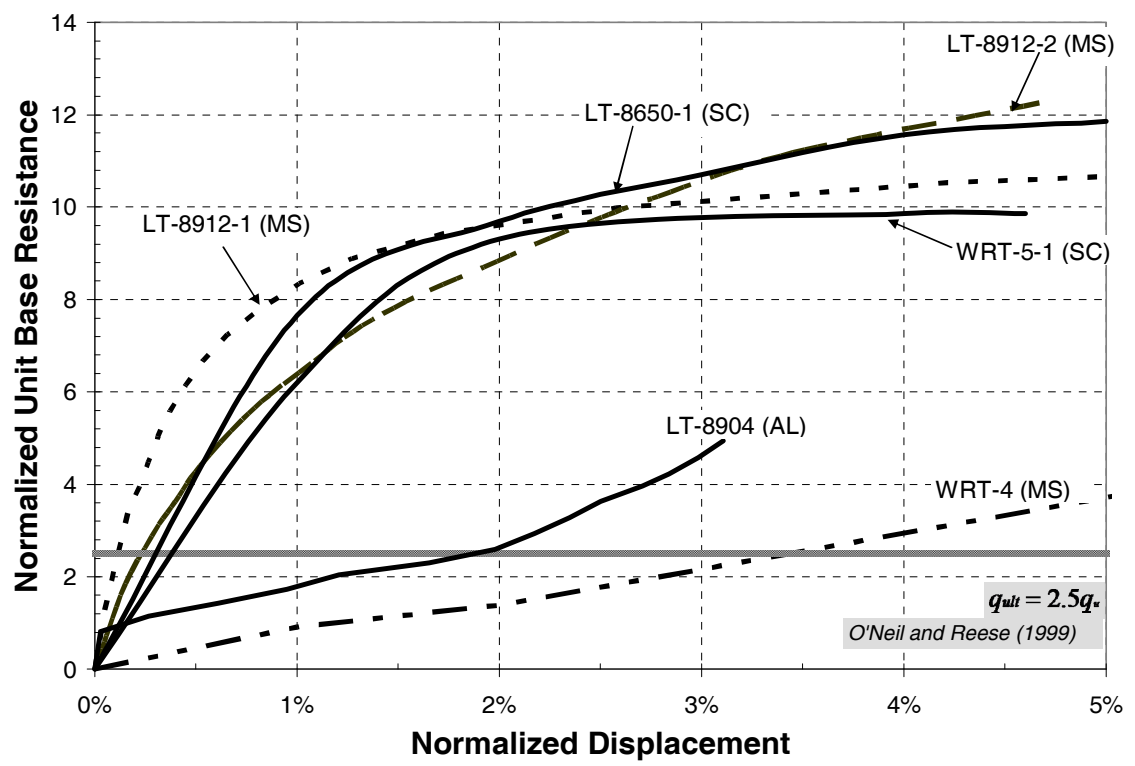

FIG. 4a. Normalized Base Resistance (Resistance/ $q_{u}$ ) vs Normalized Displacement (Shaft Deflection/Shaft Diameter in \%) 


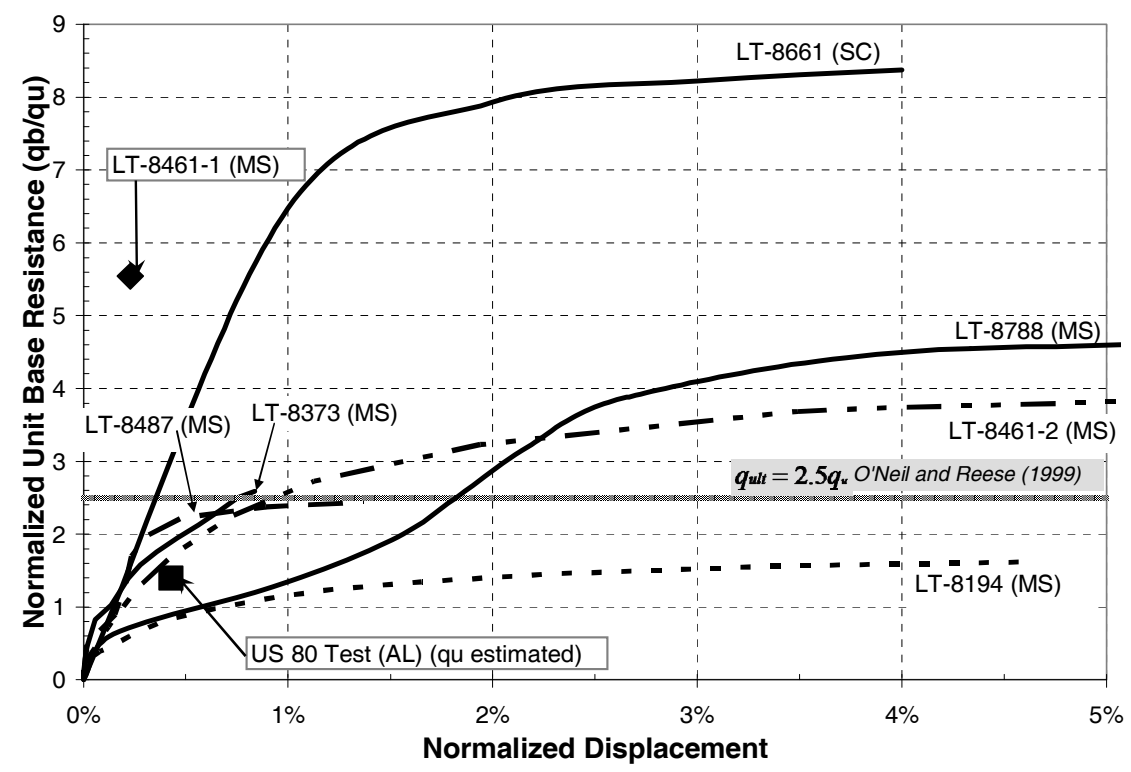

FIG. 4b. Normalized Base Resistance (Resistance/ $q_{u}$ ) vs Normalized Displacement (Shaft Deflection/Shaft Diameter in \%)

\section{CONCLUSIONS}

The load test data from chalk and marl formations suggest that drilled shafts may conservatively be designed based on unconfined compressive strength data using Eq. 1 with $\mathrm{C}=0.65$ for side shear and using Eq. 2 for base resistance. Additional discussion of the design methodology for these geomaterials is included in the final project report and in the forthcoming update to the FHWA Drilled Shaft Manual.

\section{ACKNOWLEDGMENTS}

The writers wish to acknowledge the contributions of ADSC: The International Association of Foundation Drilling, Ms. Lyndi Blackburn Davis, P.E. of the Alabama Department of Transportation, Mr. Sean Ferguson, P.E. of the Mississippi Department of Transportation, and Loadtest, Inc.

\section{REFERENCES}

Brown, D.A. and Thompson, W.R. (2008). "BRF-0008(536) Drilled Shaft Load Test Assessment, Sumter County", Research Reports for the Alabama Department of Transportation, Montgomery, AL. 
Camp, W.M. (2004). "Drilled and Driven Foundation Behavior in a Calcareous Clay", GeoSupport 2004, Orlando, FL, ASCE GSP 124, Vol 1, 1-18.

Horvath, R.G. and Kenney, T.C. (1979). "Shaft Resistance of Rock-Socketed Drilled Piers", Symposium on Deep Foundations, ASCE National Convention, Atlanta, GA, 182-214.

Kulhawy, F.H. and Phoon, K.-K. (1993). "Drilled Shaft Side Resistance in Clay Soil to Rock", Geotechnical Special Publication No. 38: Design and Performance of Deep Foundations, ASCE, Reston, VA, 172-183.

Kulhawy, F.H., Prakoso, W.A., and Akbas, S.O. (2005). "Evaluation of Capacity of Rock Foundation Sockets". Alaska Rocks 2005, Proceedings, $40^{\text {th }}$ Symposium on Rock Mechanics (CD-ROM), G. Chen, S. Huang, W. Zhou, and J. Tinucci, Eds., Anchorage, AK, June 2005.

O'Neil, M.W. and Reese, L.C. (1999). Drilled Shafts: Construction Procedures and Design Methods, FHWA Publication No. FHWA-IF-99-025, Federal Highway Administration, Washington, D.C.

Rowe, R.K. and Armitage, H.H. (1987). "A Design Method for Drilled Piers in Soft Rock”, Canadian Geotechnical Journal, Vol. 24, 1987, 126-142.

Turner, J. (2006). NCHRP Synthesis 360: Rock Socketed Shafts for Highway Structure Foundations, Transportation Research Board, Washington, D.C. 